\title{
Deformation characteristics of a single bubble in immiscible fluids
}

\author{
Jiarui Xu ${ }^{1}$, Xiaohui Zhang ${ }^{1}$, Shan Qing ${ }^{1}$, Ronghua Li $^{1}$, and Hua Wang ${ }^{2}$ \\ ${ }^{1}$ Kunming University of Science and Technology - Lianhua Campus \\ ${ }^{2}$ Kunming University of Science and Technology
}

April 28, 2021

\begin{abstract}
In order to investigate characteristics of bubble deformation in immiscible fluids, the bubble shape change during the interface and the relationship between aspect $\operatorname{ratio}(\mathrm{E})$ and dimensionless number of forces is obtained. A three-dimensional model is established and the free-floating behavior of a single bubble in immiscible fluids is numerically simulated by phase-field method. The simulation results are in good agreement with experimental results. The research shows that, in the lower liquid, the relationship between $\mathrm{E}$ and $\mathrm{We}, \mathrm{Ta}$, Re is distributed between two intersecting lines. In the upper liquid, the relationship between $\mathrm{E}$ and $\mathrm{We}$, Ta, Re is distributed between two parallel lines. Comparing the bubble deformation and the influence of the forces. Compared with gravity, the inertial force plays a leading role in the bubble shape in the lower liquid and upper liquid. Compared with the viscous force, the surface tension dominates the bubble shape in the lower liquid.
\end{abstract}

\section{Hosted file}

manuscript.pdf available at https://authorea.com/users/410751/articles/520006-deformationcharacteristics-of-a-single-bubble-in-immiscible-fluids

\section{Hosted file}

Figure.pdf available at https://authorea.com/users/410751/articles/520006-deformationcharacteristics-of-a-single-bubble-in-immiscible-fluids

\section{Hosted file}

Table.pdf available at https://authorea.com/users/410751/articles/520006-deformationcharacteristics-of-a-single-bubble-in-immiscible-fluids 